\title{
Recognition of Sepsis in Resource-Limited Settings
}

\author{
Arthur Kwizera, Neill K. J. Adhikari, Derek C. Angus, \\ Arjen M. Dondorp, Martin W. Dünser, Emir Festic, \\ Rashan Haniffa, Niranjan Kissoon, Ignacio Martin-Loeches, \\ and Ganbold Lundeg
}

\author{
A. Kwizera \\ Makerere University College of Health Sciences, Mulago National Referral Hospital, \\ Kampala, Uganda \\ N. K. J. Adhikari \\ Sunnybrook Health Sciences Centre, University of Toronto, Toronto, ON, Canada \\ D. C. Angus \\ University of Pittsburgh, Pittsburgh, PA, USA
}

\begin{abstract}
A. M. Dondorp
Faculty of Tropical Medicine, Mahidol University, Bangkok, Thailand

Academic Medical Center, University of Amsterdam, Amsterdam, The Netherlands

Nuffield Department of Clinical Medicine, Oxford Centre for Tropical Medicine and Global Health, University of Oxford, Oxford, UK
\end{abstract}

M. W. Dünser $(\bowtie)$

Department of Anesthesiology and Intensive Care Medicine, Kepler University Hospital,

Johannes Kepler University Linz, Linz, Austria

e-mail: Martin.Duenser@i-med.ac.at

E. Festic

Mayo Clinic, Jacksonville, FL, USA

R. Haniffa

Faculty of Tropical Medicine, Mahidol University, Bangkok, Thailand

N. Kissoon

British Columbia Children's Hospital, University of British Columbia,

Vancouver, CO, Canada

I. Martin-Loeches

St. James's University Hospital, Dublin, Ireland

G. Lundeg

Mongolian National University of Medical Sciences, Ulaanbaatar, Mongolia

(C) The Author(s) 2019

A. M. Dondorp et al. (eds.), Sepsis Management in Resource-limited Settings, https://doi.org/10.1007/978-3-030-03143-5_4 


\subsection{Introduction}

Sepsis is a life-threatening condition characterized by one or more organ dysfunctions due to a dysregulated host response to infection [1] or, in certain cases, due to direct pathogen effects. Sepsis is not only associated with bacterial or fungal infections but with any other infections such as viral disease, protozoal disease (e.g., malaria), or tropical infections. Although the literature suggests that sepsis is predominantly a healthcare issue in resource-rich countries, the global burden of acute infections is highest in resource-limited areas [2]. Successful sepsis management relies on various components of which early recognition is essential. In this chapter, we summarize recommendations on sepsis recognition, identification of the underlying infection and causative microbiological pathogen, as well as recognition of septic shock in resource-limited settings (Table 4.1).

\subsection{Sepsis Recognition}

Sepsis is a life-threatening condition due to acute infection that is characterized by one or more organ dysfunctions. From a pathophysiological perspective, organ dysfunction results from a dysregulated response of the host's immune system to the microbiological pathogen [3] and, in certain cases, from direct effects of the pathogen (e.g., sequestration of parasitized red blood cells in malaria, endothelial damage by NS1 [nonstructural protein 1] in dengue, tissue damage by bacterial toxins). Sepsis is not only associated with bacterial or fungal infections but with any other infection such as viral disease, protozoal diseases (e.g., malaria), or other tropical infections. As the benefits of sepsis therapy are delicately time-sensitive with improved mortality and other outcomes observed in patients receiving appropriate therapy early in the course $[3,4]$, it is critical to recognize sepsis as early as possible upon patient's presentation. Early indicators of severe disease which relate to a fatal outcome select patients needing early and urgent treatment.

The results of a large US health record database including approximately 150,000 patients with suspected acute infection revealed that a quick Sequential (Sepsisrelated) Organ Failure Assessment (qSOFA) score could help to identify patients with sepsis outside of an intensive care environment. The qSOFA score indicates the potential presence of sepsis if two of the following three indicators are fulfilled: (1) respiratory rate $\geq 22 \mathrm{bpm}$, (2) systolic blood pressure $\leq 100 \mathrm{mmHg}$, and (3) any acute change in mental state. Addition of further parameters did not relevantly improve the predictive power of this model [5]. These parameters are also included in different early warning scores [6], whose reasonable power to predict increased mortality of acutely ill patients was confirmed by studies from resource-limited settings [6-9]. A recently published study from Uganda reported that a prognostic index including respiratory rate $(\geq 30 \mathrm{bpm})$, pulse rate $(\geq 100 \mathrm{bpm})$, a mean arterial 
Table 4.1 Recommendations for the recognition of sepsis in resource-limited settings (with grading)

\begin{tabular}{|c|c|c|}
\hline 1 & $\begin{array}{l}\text { Recognition of } \\
\text { sepsis }\end{array}$ & $\begin{array}{l}\text { Define sepsis as the combination of acute infection and two of the } \\
\text { following parameters: respiratory rate } \geq 22 \mathrm{bpm} \text {, systolic blood } \\
\text { pressure } \leq 100 \mathrm{mmHg} \text {, and any acute change in mental state (1B); } \\
\text { these criteria have not been validated to recognize patients with sepsis } \\
\text { from nonbacterial infections such as malaria, dengue, or other tropical } \\
\text { infectious diseases (ungraded); diagnose malaria-induced sepsis if } \\
\text { malaria and one or more of the following clinical signs occur: } \\
\text { impaired consciousness, prostration, respiratory distress, multiple } \\
\text { convulsions, hypoglycemia, severe malarial anemia, renal impairment, } \\
\text { jaundice, malaria-induced shock, significant bleeding, and } \\
\text { hyperparasitemia (1B); diagnose dengue-induced sepsis if dengue } \\
\text { infection and any of the following clinical symptoms occur: shock, } \\
\text { respiratory distress, severe bleeding, or any organ dysfunction (1B); } \\
\text { healthcare workers, irrespective of their proficiency, should be alert to } \\
\text { consider sepsis in adults and children with acute infection of any } \\
\text { etiology (1C); recognition of sepsis in children is based on different } \\
\text { severity indicators (ungraded) }\end{array}$ \\
\hline 2 & $\begin{array}{l}\text { Identification of } \\
\text { the underlying } \\
\text { type of infection }\end{array}$ & $\begin{array}{l}\text { Take a structured patient history and perform a systematic head-to-toe } \\
\text { physical examination to identify the underlying type of infection (1A); } \\
\text { recognition of local infectious disease epidemiology is crucial } \\
\text { (ungraded); depending on their availability, perform additional } \\
\text { diagnostic evaluations such as laboratory testing and/or radiographic } \\
\text { or ultrasound imaging to identify the source of infection (1B) }\end{array}$ \\
\hline 3 & $\begin{array}{l}\text { Identification of } \\
\text { the causative } \\
\text { microbiological } \\
\text { pathogen }\end{array}$ & $\begin{array}{l}\text { If available, obtain microbiological cultures before antimicrobial } \\
\text { therapy as long as this does not relevantly delay antimicrobial therapy } \\
\text { (1A); take two or more sets of blood cultures and tissue/body } \\
\text { secretions from the site of suspected infection (1A); perform } \\
\text { microscopy and Gram staining of secretions sampled from the } \\
\text { suspected source of infection (1B); if available, test for antibiotic } \\
\text { susceptibility of cultured bacteria to guide antibiotic therapy (1B); if } \\
\text { resources to test for antibiotic susceptibility are not routinely } \\
\text { available, perform intermittent microbiological screening of } \\
\text { antimicrobial susceptibility of selected pathogens to inform empirical } \\
\text { antimicrobial strategies (2C); use rapid diagnostic tests to diagnose } \\
\text { malaria (1A); alternatively, use light microscopy of stained blood } \\
\text { smears performed by experienced staff (1A); use direct (early disease } \\
\text { phase) or indirect (intermediate or later disease phase) laboratory } \\
\text { methods to diagnose specific virus infections such as dengue, } \\
\text { influenza, or Ebola virus disease (1A); all patients with an acute } \\
\text { infection who are positive for the human immunodeficiency virus, } \\
\text { suffer from immunosuppression of other causes (e.g., malnutrition), } \\
\text { and had previous tuberculosis infection and/or close contact with } \\
\text { person suffering from tuberculosis should be screened for tuberculosis } \\
\text { coinfection (1A); use light-emitting diode microscopy of two sputum } \\
\text { smears or field PCR for the diagnosis of pulmonary tuberculosis (1A); } \\
\text { perform tuberculosis cultures in HIV-positive patients (1A) }\end{array}$ \\
\hline
\end{tabular}


Table 4.1 (continued)

\begin{tabular}{l|l}
\hline 4 & Recognition of
\end{tabular} septic shock

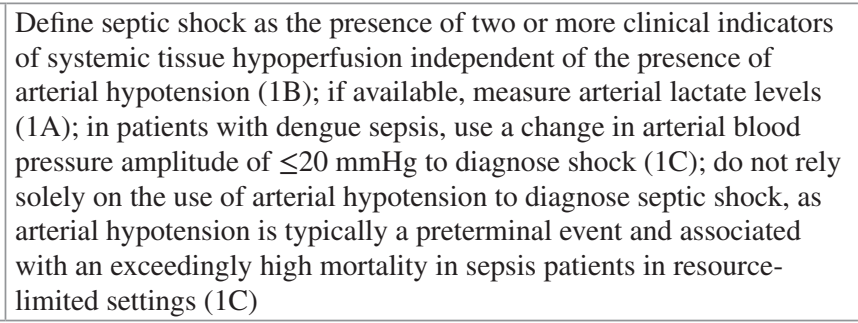

Abbreviations: $P C R$ polymerase chain reaction, $H I V$ human immunodeficiency virus

blood pressure $\geq 110$ or $\leq 70 \mathrm{mmHg}$ ), body temperature $\left(\geq 38.6\right.$ or $\left.\leq 35.6^{\circ} \mathrm{C}\right)$, and any acute change in mental state could adequately predict hospital mortality in patients with sepsis [10].

It is important to note that the definition of sepsis was established largely based on adult patients suffering from bacterial or fungal infections. The definition has so far not been validated for other infections such as malaria, dengue fever, or tropical infectious diseases, which are highly prevalent in some resource-limited settings. As pathophysiology of malaria and bacterial infections differs [11], it is well conceivable that these criteria have a lower reliability to recognize patients with sepsis due to malaria. A prospective observational study from Uganda reported that out of 216 hospitalized patients with community-acquired infection and the systemic inflammatory response syndrome, only 4\% suffered from acute malaria infection [12]. These data indicate that patients with malaria may potentially manifest with alternative signs of infection and might have been unrecognized as such. In 2015, the World Health Organization recommended diagnosing severe malaria in adults with Plasmodium falciparum asexual parasitemia and one or more of the following clinical signs: (1) impaired consciousness, (2) prostration (defined as the inability to sit, stand, or walk unassisted), (3) respiratory distress due to acidosis or pulmonary edema, (4) more than two convulsions within $24 \mathrm{~h}$, (4) hypoglycemia, (5) severe malarial anemia, (6) renal impairment, (7) jaundice, (8) malaria-induced shock (for definition see below), (8) significant bleeding, and (9) hyperparasitemia [13]. A malaria prognostic index (including Glasgow Coma Scale $<11$, admission parasitemia $>315,000 / \mu \mathrm{L}$, pigmented parasites $>20 \%$, total bilirubin $>58 \mu \mathrm{mol} / \mathrm{L}$, lactate $>5 \mathrm{mmol} / \mathrm{L})$ has shown a high sensitivity (95-100\%) and specificity (88-91\%) to predict death in Asian adults with falciparum malaria [14]. A post hoc analysis of four studies suggested that normothermia, tachypnea, impaired consciousness, oligo-anuria, shock, and hypo-/hyperglycemia independently predicted death in adults with falciparum malaria [15].

Similarly, in dengue infection, the development of shock, respiratory distress, severe bleeding, or any organ dysfunction has been recommended by the World Health Organization to characterize severe dengue and an increased risk of death [16]. The clinical usefulness and diagnostic reliability of this classification were confirmed in a multicenter study performed in seven countries including 2259 patients from Southeast Asia and Latin America [17]. 
As the burden of infection-related death in resource-limited areas is highest in children, particularly in those aged $<5$ years [18], recognition and management of sepsis in this age group is of particular importance. As children differ in several physiologic aspects from adults, the indicators of their life-threatening organ dysfunction may differ as well. These parameters are summarized in a separate part of these expert consensus recommendations dedicated to pediatric sepsis.

One of the key challenges in resource-limited areas is the lack of well-trained healthcare workers, particularly physicians specialized in emergency and critical care medicine $[19,20]$. Therefore, it appears unreasonable to limit recognition of sepsis to physicians only. Both physicians and nonphysicians (e.g., medical officers, nurses, and advanced level practitioners) need to be aware of and be able to recognize sepsis. However, they may require specific training and/or experience to do so [21]. Given that the vast majority of children with sepsis in resource-limited areas are presumably managed by non-pediatricians, it is also important that healthcare staff in resource-limited areas is aware of and trained in the specific characteristics of sepsis recognition in children [22]. A shortage in resources should not impede reliable and timely recognition of sepsis as this can generally be achieved using clinical skills only. Similarly, severity of diseases caused by malaria and dengue can be assessed largely by clinical signs. However, to recognize specific symptoms of malaria-induced sepsis or to calculate the malaria prognostic index, it is necessary to determine base deficit, lactate, and total bilirubin and creatinine or urea levels, which may not be routinely available in resource-limited settings.

Sepsis is defined as a life-threatening organ dysfunction due to a dysregulated host response to acute infection or, in certain cases, due to direct effects of the pathogen. Sepsis is not only associated with bacterial or fungal infections but with any other infection such as viral disease, protozoal infections (e.g., malaria), or tropical infections (ungraded). We recommend defining sepsis in adults as the combination of acute infection and the presence of two of the following three parameters: (1) respiratory rate $\geq 22 \mathrm{bpm}$, (2) systolic blood pressure $\leq 100 \mathrm{mmHg}$, and (3) any acute change in mental state (1B). These criteria have not been validated to recognize patients with sepsis from nonbacterial infections such as malaria, dengue, or other tropical infectious diseases (ungraded). Until data confirm the predictive value of the new sepsis definition in malaria, we recommend diagnosing malaria-induced sepsis if malaria and one or more of the following clinical signs occur: impaired consciousness, prostration, respiratory distress, multiple convulsions, hypoglycemia, severe malarial anemia, renal impairment, jaundice, malaria-induced shock, significant bleeding, and hyperparasitemia (1B). Until data confirm the predictive value of the new sepsis definition in dengue, we recommend diagnosing dengue-induced sepsis if dengue infection and any of the following clinical symptoms occur: shock, respiratory distress, severe bleeding, or any organ dysfunction (1B). We recommend that healthcare workers, irrespective of their proficiency, should be alert to consider sepsis in adults and children with acute infection of any etiology (1C). Recognition of sepsis in children is based on different severity indicators (ungraded). These are summarized in another chapter of this book. 


\subsection{Identification of the Underlying Type of Infection}

Recognition of acute infection is paramount for both sepsis diagnosis and management. Acute infection can be caused by various microbiological pathogens-bacteria, viruses, parasites, or fungi. The epidemiology of infectious diseases differs globally. While bacterial and fungal infections are observed everywhere in the world, malaria, dengue, and tropical infectious diseases are typically encountered in Central and South America, sub-Saharan Africa, and southern parts of Asia [23]. Although clear data on the epidemiology of sepsis are missing, the global mortality of malaria and thereby the burden of malaria-induced sepsis appear to be exceptionally high in resource-limited countries, particularly in sub-Saharan Africa, India, and Southeast Asia [24]. Tuberculosis is a chronic but sometimes acute bacterial infection caused by Mycobacterium spp., highly prevalent in many resource-limited areas [25]. While in high- and upper-middle-income countries, only lower respiratory tract infections are ranked (sixth) among the top ten causes of death; three and four infectious diseases (excluding HIV/AIDS) are among the top ten causes of death in lower-middle- and low-income countries, respectively. In low-income countries, lower respiratory tract infections represent the most common cause of death followed by HIV/AIDS and diarrheal diseases [26]. Viral causes of sepsis, such as dengue, often occur in epidemics.

Clinical skills of structured history taking and systematic physical examination are essential to identify the underlying type of infection. Nonspecific signs of infection include fever, chills, fatigue, malaise, and muscle/joint aches. If associated with a low risk of harm for the patient, sites of suspected infections (e.g., abscess, joints, effusion) can be punctured or incised to verify the infectious focus and sample secretions or tissue for laboratory work-up [2]. Selected laboratory parameters can assist in making the diagnosis of acute infection (e.g., the white blood cell count) but are neither highly sensitive nor specific [27-32]. Diagnostic imaging techniques, where available and preferably portable (e.g., X-ray, ultrasound) [33-35], can be used to answer specific diagnostic questions. Given its increasing portability and availability, the role of ultrasound to diagnose abdominal, joint/soft tissue, and lung infections in resource-limited countries is emphasized [36].

As mainly clinical skills are required, a lack of resources does not relevantly impede identification of the underlying infection. Given that the majority of laboratories in resource-limited settings are capable of routinely determining the white blood cell count [36-38], this parameter may be useful to support the diagnosis of an acute infection. Although ultrasound has been increasingly available in resourcelimited settings [36], in many healthcare facilities, ultrasound is not always available, as machines are routinely operated only by selected healthcare workers [39]. In addition, installation of ultrasound services in resource-limited hospitals is usually associated with substantial costs. Maintenance of ultrasound machines is another challenge in these settings. Similarly, X-ray machines are frequently immobile and require supply materials such as X-ray films.

We recommend taking a structured patient history and performing a systematic head-to-toe physical examination to identify the underlying type of infection (1A). 
Thereby, recognition of local epidemiology of infectious diseases is crucial (ungraded). Depending on their availability/affordability, we recommend performing additional diagnostic evaluations such as laboratory testing and/or radiographic or ultrasound imaging to identify the source of infection, as guided by the history and physical examination (1B).

\subsection{Identification of the Causative Microbiological Pathogen}

Definitive (as opposed to empiric) antimicrobial therapy requires identification of the microbiological pathogen of infection [3]. Appropriate antimicrobial therapy is one of the cornerstones of successful sepsis management [3, 4, 40-42]. Knowledge of the causative organism and its susceptibility to antimicrobial agents is a prerequisite for appropriate antimicrobial therapy [3]. Different diagnostic techniques are required for identification of the infectious agents causing bacterial infection, tuberculosis, malaria, and viral diseases.

Microbiological methods are used to specify bacteria and fungi from sampled body fluids and blood as well as to test their susceptibility to antibiotic agents. Microscopy and Gram staining are simple and rapid techniques to identify bacteria and fungi in the sputum, urine, cerebrospinal fluid, ascites, and other body secretions [43-49]. The appearance and staining of bacteria can categorize (Gram positive/negative) and identify selected bacterial species (e.g., meningococci, pneumococci, staphylococci), thus allowing for prompt adjustment of empiric antibiotic therapy. Microbiological cultures of body secretions are the gold standard to grow and specify bacteria. Cultivating bacteria from the blood requires special media known as blood cultures. To achieve a reasonable sensitivity, two or more sets of blood cultures from different puncture sites or indwelling catheters need to be sampled in a sterile fashion [50]. As the shorter time period between the sepsis diagnosis and administration of an appropriate antimicrobial agent may reduce mortality [4], sampling of blood or body secretions for microbiological work-up should not relevantly delay initiation of antimicrobial therapy (e.g., $<45 \mathrm{~min}$ [3]). The knowledge of antimicrobial susceptibility of the causative pathogen is of crucial importance as any potential resistance of microbiological pathogens against antimicrobial agents may result in inadequate antibiotic therapy. While antimicrobial resistance is a global challenge, the incidence of multidrug resistance is particularly high in many resource-limited areas with rates of resistant bacteria approaching as high as 50\% [51-55]. This could explain partially why an observational study from Uganda did not observe a difference in mortality between sepsis patients who received and did not receive an empiric antibiotic therapy [56]. Similarly, resistance of Plasmodium falciparum to certain antimalarial drugs such as artemisinin has spread throughout mainland Southeast Asia and has also been detected in subSaharan Africa [57-59].

Patients with an acute infection who have a risk of being (co-) infected with tuberculosis should be screened for tuberculosis. Common risk factors are HIV 
infection, malnutrition, previous tuberculosis infection, and close contact to persons suffering from tuberculosis (e.g., household members, prisoners, healthcare personnel) [60-62]. A study from Uganda reported that one in four HIV-infected patients with severe sepsis had Mycobacterium tuberculosis bacteremia [63]. The 2007 WHO international policy on tuberculosis detection recommends light-emitting diode microscopy of two sputum smears for the diagnosis of pulmonary tuberculosis infection [64]. In children, gastric aspirates can be examined alternatively to induced sputum samples. A novel field nucleic acid amplification test (Xpert MTB/ RIF) yields diagnostic results and information on rifampicin resistance under $2 \mathrm{~h}$ [65]. Despite a more rapid and frequent diagnosis of tuberculosis with this technique, concerns remain as relevant patient outcomes have not been affected so far. Although sputum examination using Ziehl-Neelsen microscopy for acid-fast bacteria is insensitive in HIV-positive subjects, it is frequently performed in laboratories of resource-limited areas, as conventional fluorescence or light-emitting diode microscopy is not commonly available. WHO guidelines recommend performance of tuberculosis cultures in HIV-positive patients [64].

Light microscopy and rapid diagnostic tests are the laboratory methods commonly used to diagnose malaria. Light microscopy of Giemsa-stained blood smears is the standard method applied in many endemic areas to identify Plasmodium spp. and estimate parasite density [66, 67]. Depending on the examiner's experience, sensitivity varies but was shown to be very high in expert hands [68]. However, this method is labor intensive and requires specific training [69]. Antigen-detecting rapid diagnostic tests, on the other hand, do not depend on laboratory infrastructure and can be performed by non-laboratory medical personnel [70]. The sensitivity and specificity of rapid diagnostic tests are high (93-98\%) and superior to that of light microscopy [71]. As rapid diagnostic tests only yield qualitative results, parasite density cannot be assessed with this method [70]. In addition, depending on the regional malaria epidemiology, different rapid diagnostic tests are required to detect and distinguish between plasmodium species [70].

Laboratory diagnosis of viral diseases, such as dengue, influenza, or Ebola, typically depends on the duration of the illness. During the early phases of infection, virus identification is achieved by direct methods (e.g., detection of viral components or cell cultures), whereas during later phases (after 5-7 days) indirect methods (e.g., serologic detection of serum IgM) are used [16, 72]. For certain viruses, rapid antigen detection tests are available yielding results within a few hours [16].Many of these tests have shown a high sensitivity and specificity such as a point-of-care rapid diagnostic test to detect the Ebola virus [73].

Laboratories in resource-limited areas often lack regular supply of materials to perform microbiological cultures and test for antibiotic susceptibility due to irregular availability of these materials on the local and national markets as well as due to the high cost [36-38]. On the other hand, microscopy and Gram staining are available in many of the laboratories [36-38]. Microscopic analysis and Gram staining can specify selected bacteria and fungi but do not give information on antibiotic susceptibility. In cases where routine microbiological cultures and susceptibility 
testing are not available, determination of the most common pathogens (e.g., pneumococci, staphylococci, Escherichia coli, Mycobacterium tuberculosis, Plasmodium falciparum, etc.) for each infection site as well as their antimicrobial susceptibility may help to optimize empiric antimicrobial therapy. Accordingly, the World Alliance Against Antibiotic Resistance recommends collection of information on antibiotic resistance in each country/region [74].This recommendation is in line with that of the World Health Organization to regularly monitor drug efficacy for the first-line antimalarial drugs at regular intervals [75].

Laboratory methods to identify malaria are commonly available at healthcare facilities in areas where malaria is endemic [36-38]. The costs of rapid diagnostic tests are higher than those of light microscopy, despite that their use in Africa has increased substantially during the recent years [76]. Regarding tuberculosis detection using polymerase chain reaction tests or virus identification, laboratory tests yielding a high sensitivity and specificity typically require complex technologies, infrastructure requirements, and staff expertise and imply high costs. On the other hand, serologic tests are more affordable although they similarly require specific laboratory facilities which may not be available in many resource-limited settings [36-38]. This may change in cases of viral disease epidemics such as the recent Ebola virus disease epidemic in Western Africa [77]. None of the tests are associated with any direct risks for the patient. However, contamination of microbiological cultures and false-positive or false-negative results of laboratory tests bear the risk of over- or undertreatment, both of which may be associated with harm.

If available/affordable, we recommend obtaining microbiological cultures before antimicrobial therapy as long as this does not relevantly delay antimicrobial therapy (1A). We recommend taking two or more sets of blood cultures and/or tissue/body secretions from the site of suspected infection (1A). We recommend performing microscopy and Gram staining of secretions sampled from the suspected source of infection (1B). If available/affordable, we recommend testing for antibiotic susceptibility of cultured bacteria to guide antibiotic therapy (1B). If resources to test for antibiotic susceptibility are not routinely available, we suggest performing intermittent microbiological screening of antimicrobial susceptibility of selected pathogens to inform empirical antimicrobial strategies (1C). We recommend using rapid diagnostic tests to diagnose malaria (1A). Alternatively, we recommend light microscopy of stained blood smears performed by experienced staff $(1 \mathrm{~A})$. We recommend using direct (early disease phase) or indirect (intermediate or later disease phase) laboratory methods to diagnose specific virus infections such as dengue, influenza, or Ebola virus disease (1A). All patients with an acute infection who are positive for the human immunodeficiency virus, suffer from immunosuppression of other causes (e.g., malnutrition), and had previous tuberculosis infection and/or close contact with person suffering from tuberculosis should be screened for tuberculosis coinfection (1A). We recommend light-emitting diode microscopy of two sputum smears for the diagnosis of pulmonary tuberculosis (1A). Whenever available/affordable, we recommend using polymerase chain reaction tests (e.g., Gene Xpert) to diagnose tuberculosis or perform tuberculosis cultures in HIV-positive patients (1A). 


\subsection{Recognition of Septic Shock}

Shock is defined as inadequate systemic tissue perfusion with cellular dysoxia/ hypoxia [78]. Septic shock has recently been defined as arterial hypotension requiring vasopressor therapy to maintain mean arterial blood pressure at $65 \mathrm{mmHg}$ or greater together with a serum lactate level greater than $2 \mathrm{mmol} / \mathrm{L}$ after adequate fluid resuscitation [79]. Systemic tissue hypoperfusion is a critical cofactor in the development of organ dysfunction and death in patients with sepsis [3, 79]. Recognition of septic shock is therefore essential to recognize sepsis patients with a particularly high risk of death.

Critically ill patients with abnormal peripheral perfusion (e.g., cold and clammy skin) following initial resuscitation have more severe metabolic derangements and organ dysfunction than subjects with normal peripheral perfusion [80]. In early septic shock due to bacterial infection, prolonged capillary refill time is strongly associated with organ dysfunction and mortality [81]. Similarly, prolonged capillary refill time is an indicator of disease severity and a high risk of death in malaria [82] and dengue infection [83]. The extent of skin mottling in the lower extremities is associated with organ dysfunction and mortality in sepsis [84]. Given that of all internal organs the kidneys exhibit the highest autoregulatory threshold, renal blood flow is the first to decline in case of decreased cardiac output or peripheral vasodilation [85]. Thus, any episode of oliguria $(<0.5 \mathrm{ml} / \mathrm{kg} / \mathrm{h})$ potentially indicates renal hypoperfusion. Observational studies found that the longer time during which urine output remains $<0.5 \mathrm{~mL} / \mathrm{kg} / \mathrm{h}$ is associated with higher morbidity and mortality in critically ill patients [86]. Elevated lactate levels also predict increased morbidity and mortality in patients with sepsis $[87,88]$. Moreover, the duration of hyperlactatemia and the rate of lactate clearance are associated with organ dysfunction and mortality in sepsis. Studies from resource-limited settings confirmed that hyperlactatemia is associated with a high degree of illness severity and an increased mortality from sepsis independent of the underlying pathogen [14, 89]. If patients with sepsis and signs of systemic tissue hypoperfusion develop arterial hypotension [defined as a systolic arterial blood pressure $<90 \mathrm{mmHg}$ or a mean arterial blood pressure $<65 \mathrm{mmHg}$ ], the risk of death was shown to be excessively high in resource-limited settings [89-91]. Per the authors' experience, occurrence of arterial hypotension in septic patients with systemic tissue hypoperfusion is typically a preterminal sign, as the therapeutic requirements in these patients often exceed the capabilities of resource-limited healthcare facilities. In patients with severe malaria, arterial hypotension is rare and when present is often associated with bacterial coinfection [11, 13, 92]. The World Health Organization defined dengue shock by the presence of an arterial blood pressure amplitude (systolic minus diastolic arterial blood pressure) $\leq 20 \mathrm{mmHg}$ [16]. In dengue shock, systolic arterial blood pressure remains normal or even elevated but can drop rapidly preceding terminal cardiovascular collapse [16]. Studies have suggested that the following clinical symptoms result from early plasma leakage and herald dengue shock: abdominal pain, hepatomegaly, high or increasing hematocrit levels, rapid decrease in platelet count, serosal effusions, mucosal bleeding, and lethargy or restlessness [16]. 
A shortage of resources does not impede the ability to recognize septic shock as the diagnosis is mainly based on clinical indicators. Specific training of healthcare workers to recognize these clinical signs is, however, essential. Using skin mottling to assess skin perfusion in dark complexed patients may not be feasible. However, assessment of capillary refill time is a meaningful alternative that demonstrated similar predictive value for organ dysfunction and death in sepsis [81]. Costs for lactate measurements may be relevant and, in some settings, may even impede use of arterial lactate in sepsis patients. There are no direct patient risks related to diagnosing shock by using clinical techniques. Despite its strong predictive power, arterial lactate measurements are not routinely available or affordable in many resource-limited healthcare facilities [36-38].

We recommend defining septic shock as the presence of two or more clinical indicators of systemic tissue hypoperfusion independent of the presence of arterial hypotension (1B). If available, we recommend measuring arterial lactate levels in patients with sepsis (1A). In patients with dengue sepsis, we recommend using a reduction in the arterial blood pressure amplitude $\leq 20 \mathrm{mmHg}$ to diagnose shock (1C). We recommend against relying solely on arterial hypotension as a diagnostic criterion for the diagnosis of septic shock, as arterial hypotension is typically a preterminal event and associated with an exceedingly high mortality in sepsis patients in resource-limited settings (1C).

\subsection{Conclusions}

Sepsis is not only associated with bacterial or fungal infections but with any other infection such as viral disease, protozoal disease (e.g., malaria), or tropical infections. We provided a set of simple, readily available, and affordable recommendations on how to recognize sepsis, identify the underlying type of infection, identify the causative microbiological pathogen, and recognize septic shock in resourcelimited settings. As most evidence originates from resource-rich settings, there is an urgent need for related research in resource-limited settings.

\section{References}

1. Singer M, Deutschman CS, Seymour CW, Shankar-Hari M, Annane D, Bauer M, Bellomo R, Bernard GR, Chiche JD, Coopersmith CM, Hotchkiss RS, Levy MM, Marshall JC, Martin GS, Opal SM, Rubenfeld GC, van der Poll T, Vincent JL, Angus DC. The third international consensus definitions for sepsis and septic shock (Sepsis-3). JAMA. 2016;315:801-10.

2. The 10 leading causes of death by country income group. WHO factsheets. 2012. http://www. who.int/mediacentre/factsheets/fs 310/en/index1.html.

3. Angus DC, van der Poll T. Severe sepsis and septic shock. N Engl J Med. 2013;369:840-51.

4. Kumar A, Roberts D, Wood KE, Light B, Parrillo JE, Sharma S, Suppes R, Feinstein D, Zanotti S, Taiberg L, Gurka D, Kumar A, Cheang M. Duration of hypotension before initiation of effective antimicrobial therapy is the critical determinant of survival in human septic shock. Crit Care Med. 2006;34:1589-96. 
5. Seymour CW, Liu VX, Iwashyna TJ, Brunkhorst FM, Rea TD, Scherag A, Rubenfeld G, Kahn JM, Shankar-Hari M, Singer M, Deutschman CS, Escobar GJ, Angus DC. Assessment of clinical criteria for sepsis: for the third international consensus definitions for sepsis and septic shock (Sepsis-3). JAMA. 2016;315:762-74.

6. Ghanem-Zoubi NO, Vardi M, Laor A, Weber G, Bitterman H. Assessment of disease-severity scoring systems for patients with sepsis in general internal medicine departments. Crit Care. 2011;15:R95.

7. Rylance J, Baker T, Mushi E, Mashaga D. Use of an early warning score and ability to walk predicts mortality in medical patients admitted to hospitals in Tanzania. Trans R Soc Trop Med Hyg. 2009;103:790-4.

8. Bulut M, Cebicci H, Sigirli D, Sak A, Durmus O, Top AA, Kaya S, Uz K. The comparison of modified early warning score with rapid emergency medicine score: a prospective multicentre observational cohort study on medical and surgical patients presenting to emergency department. Emerg Med J. 2014;31:476-81.

9. Opio MO, nansubuga G, Kellett J, Clifford M, Murray A. Performance of TOTAL, in medical patients attending a resource-poor hospital in Sub-Saharan Africa and a small Irish rural hospital. Acute Med. 2013;12:135-40.

10. Asiimwe SB, Abdallah A, Ssekitoleko R. A simple prognostic index based on admission vital signs data among patients with sepsis in a resource-limited setting. Cirt Care. 2015;19:86.

11. White NJ, Pukrittayakamee S, Hien TT, Faiz MA, Mokuolu OA, Dondorp AM. Malaria. Lancet. 2014;383:723-35.

12. Auma MA, Siedner MJ, Nyehangane D, Nalusaji A, Nakaye M, Mwanga-Amumpaire J, Muhindo R, Wilson LA, Boum Y II, Moore CC. Malaria is an uncommon cause of adult sepsis in south-western Uganda. Malar J. 2013;12:146.

13. The World Health Organization. Guidelines for the management of malaria. 3rd ed. Geneva: World Health Organization; 2015. isbn:978-92-4-154912-7.

14. Newton PN, Stepniewska K, Dondorp A, Kamolrat S, Chierakul W, Krishna S, Davis TME, Suputtamongkol Y, Angus B, Pukrittayakamee S, Ruangveerayuth R, Hanson J, Day NPJ, White NJ. Prognostic indicators in adults hospitalized with falciparum malaria in Western Thailand. Malar J. 2013;12:229.

15. Hanson J, Lee SJ, Mohanty S, Faiz MA, Anstey NM, Price RN, Charunwatthana P, Yunus EB, Mishra SK, Tjitra E, Rahman R, Nosten F, Htut Y, Maude RJ, ThiHong Chau T, HoanPhu N, Tinh Hien T, White NJ, Day NPJ, Dondorp AM. PLoS One. 2014;9:e87020.

16. Simmons CP, Farrar JJ, van Vinh Chau N, Wills B. Dengue. N Engl J Med. 2012;366:1423-32.

17. Alexander N, Balmaseda A, Coelho IC, Dimaano E, Hien TT, Hung NT, Jänisch T, Kroeger A, Lum LC, Martinez E, Siqueira JB, Thuy TT, Villalobos I, Villegas E, Wills B. Multicentre prospective study on dengue classification in four Southeast Asian and three Latin American countries. Tropical Med Int Health. 2011;16:936-48.

18. The World Health Organization. The top 10 causes of death. http://www.who.int/mediacentre/ factsheets/fs310/en/index2.html. Accessed 8 Sept 2015.

19. Jochberger S, Ismailova F, Lederer W, Mayr VD, Luckner G, Wenzel V, Ulmer H, Hasibeder WR, Dünser MW, "HelfenBerührt" Study Team. Anesthesia and its allied disciplines in the developing world: a nationwide survey of the Republic of Zambia. Anesth Analg. 2008;106:942-8.

20. Dünser MW, Bataar O, Tsenddorj G, Lundeg G, Jochberger S, Jakob S, "HelfenBerührt” Study Team. Intensive care medicine in Mongolia's 3 largest cities: outlining the needs. J Crit Care. 2009;24:469.e1-6.

21. Peltola L, Goddia C, Namboya F, Brunkhorst FM, Pollach G. Sepsis-knowledge of nonphysician personnel in Africa. A cross-sectional study in Malawian district hospitals. Med Klin Intensivmed Notfmed. 2015;110:49-54.

22. Kissoon N. Out of Africa—a mother's journey. Pediatr Crit Care Med. 2011;12:73-9.

23. Gething PW, Patil AP, Smith DL, Guerra CA, Elyazar IR, Johnston GL, Tatem AJ, Hay SI. A new world malaria map: Plasmodium falciparum endemicity in 2010. Malar J. 2011;10:378. 
24. Snow RW, Guerra CA, Noor AM, Myint HY, Hay SI. The global distribution of clinical episodes of Plasmodium falciparum malaria. Nature. 2005;434:214-7.

25. Zumla A, Raviglione M, Hafner R, von Reyn CF. Tuberculosis. N Engl J Med. 2013;368:745-55.

26. The 10 leading causes of death by country income group. 2012. WHO factsheets. http://www. who.int/mediacentre/factsheets/fs310/en/index1.html. Accessed 23 Aug 2015.

27. Chan YL, Tseng CP, Tsay PK, Chang SS, Chiu TF, Chen JC. Procalcitonin as a marker of bacterial infection in the emergency department: an observational study. Crit Care. 2004;8:R12-20.

28. Chan YL, Liao HC, Tsay PK, Chang SS, Chen JC, Liaw SJ. C-reactive protein as an indicator of bacterial infection of adult patients in the emergency department. Chang Gung Med J. 2002;25:437-45.

29. Cheval C, Timsit JF, Garrouste-Orgeas M, Assicot M, De Jonghe B, Misset B, Bohuon C, Carlet J. Procalcitonin (PCT) is useful in predicting the bacterial origin of an acute circulatory failure in critically ill patients. Intensive Care Med. 2000;26(Suppl 2):S153-8.

30. Lagerström F, Engfeldt P, Holmberg H. C-reactive protein in diagnosis of community-acquired pneumonia in adult patients in primary care. Scand J Infect Dis. 2006;38:964-9.

31. Liu A, Bui T, Van Nguyen H, Ong B, Shen Q, Kamalasena D. Serum C-reactive protein as a biomarker for early detection of bacterial infection in the older patient. Age Ageing. 2010;39:559-65.

32. Póvoa P, Coelho L, Almeida E, Fernandes A, Mealha R, Moreira P, Sabino H. C-reactive protein as a marker of infection in critically ill patients. Clin Microbiol Infect. 2005;11:101-8.

33. Ifergan J, Pommier R, Brion MC, Glas L, Rocher L, Bellin MF. Imaging in upper urinary tract infections. Diagn Interv Imaging. 2012;93:509-19.

34. Cardinal E, Bureau NJ, Aubin B, Chhem RK. Role of ultrasound in musculoskeletal infections. Radiol Clin North Am. 2001;39:191-201.

35. Diefenthal HC, Tashiian J. The role of plain films, CT, tomography, ultrasound, and percutaneous needle aspiration in the diagnosis of inflammatory lung disease. Semin Respir Infect. 1988;3:83-105.

36. Chavez MA, Naithani N, Gilman RH, Tielsch JM, Khatry S, Ellington LE, Miranda JJ, Gurung G, Rodriguez S, Checkley W. Agreement between the World Health Organization and lung consolidation identified using point-of-care ultrasound for the diagnosis of childhood pneumonia by general practitioners. Lung. 2015;193:531-8.

37. Baelani I, Jochberger S, Laimer T, Rex C, Baker T, Wilson IH, Grander W, Dünser MW. Identifying resource needs for sepsis care and guideline implementation in the Democratic Republic of the Congo: a cluster survey of 66 hospitals in four eastern provinces. Middle East J Anaesthesiol. 2012;21:559-75.

38. Bataar O, Lundeg G, Tsenddorj G, Jochberger S, Grander W, Baelani I, Wilson I, Baker T, Dünser MW, HelfenBerührt Study Team. Nationwide survey on resource availability for implementing current sepsis guidelines in Mongolia. Bull World Health Organ. 2010;88:839-46.

39. Harris RD, Cho JY, Deneen DR. Compact ultrasound donations to medical facilities in lowresource countries: a survey-based assessment of the current status and trends. J Ultrasound Med. 2012;31:1255-9.

40. Kollef MH, Sherman G, Ward S, Fraser VJ. Inadequate antimicrobial treatment of infections: a risk factor for hospital mortality among critically ill patients. Chest. 1999;115:462-74.

41. Ibrahim EH, Sherman G, Ward S, Fraser VJ, Kollef MH. The influence of antimicrobial treatment of bloodstream infections on patient outcomes in the ICU setting. Chest. 2000;118:146-55.

42. Paul M, Shani V, Muchtar E, Kariv G, Robenshtok E, Leibovici L. Systematic review and meta-analysis of the efficacy of appropriate empiric antibiotic therapy for sepsis. Antimicrob Agents Chemother. 2010;54:4851-63.

43. Holm S, Wahlin A, Wahlqvist L, Wedrén H, Lundgren B. Urine microscopy as screening method for bacteriuria. Acta Med Scand. 1982;211:209-12.

44. Barbin GK, Thorley JD, Reinarz JA. Simplified microscopy for rapid detection of significant bacteriuria in random urine specimens. J Clin Micorbiol. 1978;7:286-9. 
45. Salih MA, el Hag AI, Sid Ahmed H, Bushara M, Yasin I, Omer MI, Hofvander Y, Olcen P. Endemic bacterial meningitis in Sudanese children: aetiology, clinical findings, treatment and short-term outcome. Ann Trop Paediatr. 1990;10:203-10.

46. Leman P. Validity of urinalysis and microscopy for detecting urinary tract infection in the emergency department. Eur J Emerg Med. 2002;9:141-7.

47. Alausa KO, Osoba AO, Montefiore D, Sogbetun OA. Laboratory diagnosis of tuberculosis in a developing country 1968-1975. Afr J Med Med Sci. 1977;6:103-8.

48. Shameem S, Vinod Kumar CS, Neelagund YF. Bacterial meningitis: rapid diagnosis and microbial profile: a multicentered study. J Commun Dis. 2008;40:111-20.

49. Heyman SN, Ginosar Y, Niel L, Amir J, Marx N, Shapiro M, Maayan S. Meningococcal meningitis among Rwandan refugees: diagnosis, management, and outcome in a field hospital. Int J Infect Dis. 1998;2:137-42.

50. Shafazand S, Weinacker AB. Blood cultures in the critical care unit: improving utilization and yield. Chest. 2002;122:1727-36.

51. Bataar O, Khuderchuluun C, Lundeg G, Chimeddorj S, Brunauer A, Gradwohl-Matis I, Duenser MW. Rate and pattern of antibiotic resistance and microbiological cultures of sepsis patients in a low-middle-income country's ICU. Middle East J Anaesthesiol. 2013;22:293-300.

52. Iroezindu MO, El C, Isiguzo GC, Mbata GC, Onyedum CC, Kl O, Okoli LE. Sputum bacteriology and antibiotic sensitivity patterns of community-acquired pneumonia in hospitalized adult patients in Nigeria: a 5-year multicentre retrospective study. Scand J Infect Dis. 2014;46:875-87.

53. Matute AJ, Brouwer WP, Hak E, Delgado E, Alonso E, Hoepelman IM. Aetiology and resistance patterns of community-acquired pneumonia in León, Nicaragua. Int J Antimicrob Agents. 2006;28:423-7.

54. Biadglegne F, Rodloff AC, Sack U. Review of the prevalence and drug resistance of tuberculosis in prisons: a hidden epidemic. Epidemiol Infect. 2015;143:887-900.

55. Chittawatanarat K, Jaipakdee W, Chotirosniramit N, Chandacham K, Jirapongcharoenlap T. Microbiology, resistance patterns, and risk factors of mortality in ventilator-associated bacterial pneumonia in a Northern Thai tertiary-care university based general surgical intensive care unit. Infect Drug Resist. 2014;7:203-10.

56. Jacob ST, Moore CC, Banura P, Pinkerton R, Meya D, Opendi P, Reynolds SJ, Kenya-Mugisha N, Mayanja-Kizza H, Scheld WM, Promoting Resource-Limited Interventions for Sepsis Management in Uganda (PRISM-U) Study Group. Severe sepsis in two Ugandan hospitals: a prospective observational study of management and outcomes in a predominantly HIV-1 infected population. PLoS One. 2009;4:e7782.

57. Dondorp AM, Nosten F, Yi P, et al. Artemisinin resistance in Plasmodium falciparum malaria. N Engl J Med. 2009;361:455-67.

58. Ashley EA, Dhorda M, Fairhurst RM, et al. Spread of artemisinin resistance in Plasmodium falciparum malaria, vol. 371; 2014. p. 411-23.

59. Kamau E, Campino S, Amenga-Etego L, et al. K13-propeller polymorphisms in Plasmodium falciparum parasites from sub-Saharan Africa. J Infect Dis. 2015;211:1352-5.

60. Telisinghe L, Fielding KL, Malden JL, Hanifa Y, Churchyard GJ, Grand AD, Charalambous S. High tuberculosis prevalence in a South African prison: the need for routine tuberculosis screening. PLoS One. 2014;9:e87262.

61. Joshi R, Reingold AL, Menzies D, Pai M. Tuberculosis among health-care workers in low- and middle-income countries: a systematic review. PLoS Med. 2006;3:e494.

62. Lienhardt C, Fielding K, Sillah JS, Bah B, Gustafson P, Warndorff D, Palayew M, Lisse I, Donkor S, Diallo S, Manneh K, Adegbola R, Aaby P, Bah-Sow O, Bennett S, McAdam $\mathrm{K}$. Investigation of the risk factors for tuberculosis: a case-control study in three countries in West Africa. Int J Epidemiol. 2005;34:914-23.

63. Jacob ST, Pavlinac PB, Nakiyingi L, Banura P, Baeten JM, Morgan K, Magaret A, Manabe Y, Reynolds SJ, Liles WC, Wald A, Joloba ML, Mayanja-Kizza H, Scheld WM. Mycobacterium tuberculosis bacteremia in a cohort of HIV-infected patients hospitalized with severe sepsis in 
Uganda-high frequency, low clinical suspicion and derivation of a clinical prediction score. PLoS One. 2013;8:e70305.

64. World Health Organization. Reduction of number of smears for the diagnosis of pulmonary TB. Geneva: World Health Organization; 2007. http://www.who.int/tb/dots/laboratory/policy/ en/index 2.html.

65. McNerney R, Cunningham J, Hepple P, Zumla A. New tuberculosis diagnostics and rollout. Int J Infect Dis. 2015;32:81-6.

66. Dowling MA, Shute GT. A comparative study of thick and thin blood films in the diagnosis of scanty malaria parasitaemia. Bull World Heatlh Organ. 1966;34:249-67.

67. Payne $\mathrm{D}$. Use and limitations of light microscopy for diagnosing malaria at the primary health care level. Bull World Health Organ. 1988;66:621-6.

68. Wongsrichanalai C, Barcus MJ, Muth S, Sutamihardja A, Wernsdorfer WH. A review of malaria diagnostic tools: microscopy and rapid diagnostic test (RDT). Am J Trop Med Hyg. 2007;77(6 Suppl):119-27.

69. Murray CK, Gaser RA Jr, Magill AJ, Miller RS. Update on rapid diagnostic testing for malaria. Clin Microbiol Rev. 2008;21:97-110.

70. Wilson ML. Malaria rapid diagnostic tests. Clin Infect Dis. 2012;54:1637-41.

71. Abba K, Deeks JJ, Olliaro P, Naing CM, Jackson SM, Takwoingi Y, Donegan S, Garner P. Rapid diagnostic tests for diagnosing uncomplicated P. falciparum malaria in endemic countries. Cochrane Database Syst Rev. 2011;7:CD008122.

72. Rathakrishnan A, Sekaran SD. New development in the diagnosis of dengue infections. Expert Opin Med Diagn. 2013;7:99-112.

73. Broadhurst MJ, Kelly JD, Miller A, et al. ReEBOV antigen rapid test kit for point-ofcare and laboratory-based testing for Ebola virus disease: a field validation study. Lancet. 2015;386:867-74.

74. Carlet J. Ten tips on how to win the war against resistance to antibiotics. Intensive Care Med. 2015;41:899-901.

75. World Health Organization. Assessment and monitoring of antimalarial drug efficacy for the treatment of uncomplicated falciparum malaria. Geneva: World Health Organization; 2003. http://malaria.who.int/docs/ProtocolWHO.pdf.

76. WHO. World malaria report, 2011. Geneva: World Health Organization; 2012.

77. Walkner NF, Brown CS, Youkee D, et al. Evaluation of a point-of-care blood test for identification of Ebola virus disease at Eboalholidng units, Western Area, Sierra Leone, January to February 2015. Euro Surveill. 2015;20:21073.

78. Cecconi M, De Backer D, Antonelli M, Beale R, Bakker J, Hofer C, Jaeschke R, Mebazaa A, Pinsky MR, Teboul JL, Vincent JL, Rhodes A. Consensus on circulatory shock and hemodynamic monitoring. Task force of the European Society of Intensive Care Medicine. Intensive Care Med. 2014;40:1795-815.

79. Shankar-Hari M, Phillips GS, Levy ML, Seymour CW, Liu VX, Deutschman CS, Angus DC, Rubenfeld GD, Singer M, Sepsis Definitions Task Force. Developing a new definition and assessing new clinical criteria for septic shock: for the third international consensus definition for sepsis and septic shock (Sepsis-3). JAMA. 2016;315:775-87.

80. Lima A, Jansen TC, van Bommel J, Ince C, Bakker J. The prognostic value of the subjective assessment of peripheral perfusion in critically ill patients. Crit Care Med. 2009;37:934-8.

81. Ait-Oufella H, Bige N, Boelle PY, Pichereau C, Alves M, Bertinchamp R, Baudel JL, Galbois A, Maury E, Guidet B. Capillary refill time exploration during septic shock. Intensive Care Med. 2014;40:958-64.

82. Evans JA, May J, Ansong D, Antwi S, Asafo-Adjei E, Nguah SB, Osei-Kwakye K, Akoto AO, Ofori AO, Sambian D, Sylverken J, Busch W, Timmann C, Agbenyega T, Horstmann RD. Capillary refill time as an independent prognostic indicator in severe and complicated malaria. J Pedatir. 2006;149:676-81.

83. Biswas HH, Ortega O, Grodon A, Standish K, Balmaseda A, Kuan G, Harris E. Early clinical features of dengue virus infection in Nicaraguan children: a longitudinal analysis. PLoS Negl Trop Dis. 2012;e1562:6. 
84. Ait-Oufella H, Lemoinne S, Boelle PY, Galbois A, Baudel JL, Lemant J, Joffre J, Margetis D, Guidet B, Maury E, Offenstadt G. Mottling score predicts survival in septic shock. Intensive Care Med. 2011;37:801-7.

85. Leithe ME, Margorien RD, Hermiller JB, Unverferth DV, Leier CV. Relationship between central hemodynamics and regional blood flow in normal subjects and in patients with congestive heart failure. Circulation. 1984;69:57-64.

86. Macedo E, Malhotra R, Bouchard J, Wynn SK, Mehta RL. Oliguria is an early predictor of higher mortality in critically ill patients. Kidney Int. 2011;80:760-7.

87. Bakker J, Coffernils M, Leon M, Gris P, Vincent JL. Blood lactate levels are superior to oxygenderived variables in predicting outcome in human septic shock. Chest. 1991;99:956-62.

88. Nguyen HB, Rivers EP, Knoblich BP, Jacobsen G, Muzzin A, Ressler JA, Tomlanovich MC. Early lactate clearance is associated with improved outcome in severe sepsis and septic shock. Crit Care Med. 2004;32:1637-42.

89. Dünser MW, Bataar O, Tsenddorj G, Lundeg G, Torgersen C, Romand JA, Hasibeder WR, HelfenBerührt Study Team. Differences in critical care practice between an industrialized and a developing country. Wien Klin Wochenschr. 2008;120:600-7.

90. Bahloul M, Samet M, Chaari A, Ben Aljia N, Ben Mbarek MN, Chelly H, Dammak H, Ben Hamida C, Rekik N, Kallel H, Bouaziz M. Use of catecholamines for shock. A continuous debate. Tunis Med. 2012;90:291-9.

91. Frikha N, Mebazaa M, Mnif L, El Euch N, Abassi M, Ben Ammar MS. Septic shock in a Tunisian intensive care unit: mortality and predictive factors. 100 cases. Tunis Med. 2005;83:320-5.

92. Bruneel F, Gachot B, Timsit JF, Wolff M, Bédos JP, Régnier B, Vachon F. Shock complicating severe falciparum malaria in European adults. Intensive Care Med. 1997;23:698-701.

Open Access This chapter is licensed under the terms of the Creative Commons Attribution 4.0 International License (http://creativecommons.org/licenses/by/4.0/), which permits use, sharing, adaptation, distribution and reproduction in any medium or format, as long as you give appropriate credit to the original author(s) and the source, provide a link to the Creative Commons license and indicate if changes were made.

The images or other third party material in this chapter are included in the chapter's Creative Commons license, unless indicated otherwise in a credit line to the material. If material is not included in the chapter's Creative Commons license and your intended use is not permitted by statutory regulation or exceeds the permitted use, you will need to obtain permission directly from the copyright holder.

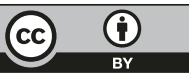

